\title{
THE CHANGES IN THE AMINO AND FATTY ACID PROFILES IN THE SEMIFINISHED FOODSTUFFS BASED ON BROILER MEAT AND COMPONENTS OF CHICKEN EGGS AFTER DIFFERENT TYPES OF THERMAL TREATMENT
}

Isabella L. Stefanova*, Liudmila V. Shakhnazarova, Anastasia Yu. Klimenkova, Inna M. Sorokina

All-Russian Scientific Research Institute of Poultry Processing Industry - Branch of the Federal State Budget Scientific Institution Federal Scientific Center “All-Russian Research and Technological Poultry Institute” of Russian Academy of Sciences, Rzhavki township, Moscow region

Keywords: broiler meat, coagulated chicken egg melange, semifinished foodstuff, thermal treatment, amino and fatty acid profiles, nutrient balance

\begin{abstract}
The changes in the amino and fatty acid profiles in the semifinished foodstuffs (SFFs) based on broiler meat and coagulated chicken egg melange after different types of thermal treatment (water or steam boiling, braising, baking, frying) were studied. The amino acid profiles were determined on Knauer analyzer; tryptophan by standard method. The biological value of the treated products was assessed using amino acid balance coefficients calculated by the method of N. N. Lipatov. It was found that the changes in the initial amino acid profiles of the SFFs were the least after water and steam boiling; braising and baking were found to increase the contents of the essential amino acids. The amino acid profiles in the treated SFFs were close to the reference values. The best criteria of their biological value (coefficient of rationality of amino acid composition, comparable redundance) were found after water and steam boiling. It was found that all types of thermal treatments insignificantly affected the parameters of fatty acid balance within the SFFs; the changes found were primarily related to slight increase in total content of saturated fatty acids and increase in total content of polyunsaturated fatty acids (PUFAs) in compare to initial profiles, by 2.64-3.88\% depending on the treatment type. The changes in $\omega-6 / \omega-3$ PUFAs ratios were more substantial especially after braising.
\end{abstract}

\section{Introduction}

The development and reinforcement of the health status in human of different ages cannot be achieved without consumption of the foodstuffs with high content of essential nutrients (well-balanced protein and fat, etc.). The increasing demand for these foodstuffs is a constant trend of the food market worldwide.

The everyday consumption of poultry meat can provide consumers with vitally important essential amino acids (tryptophan, lysine, and methionine) in the most beneficial ratio 1:3:3 [1,2]; these amino acids take part in the biosynthesis of different tissue proteins and also play certain special functions in human. However, the protein of broiler meat is known to be valine-deficient and hence the foodstuffs fully balanced for all essential amino acids should be additionally corrected for the valine content since the deficit (or absence) of this amino acid can result in the severe dysfunctions of the central nervous system and myasthenia [3].

Another important aspect of healthy nutrition is the balance in the fatty acid profile of the dietary lipids since saturated (SFA), monounsaturated (MUFA), and polyunsaturated (PUFA) fatty acids are the main structural and functional components of cell membranes. The special attention should be paid to the essential PUFAs which cannot be synthesized by animals and human and should be provided via feed or food, primarily linolic (LA, C18:2, $\omega-6)$ and $\alpha$-linoleic (ALA, C18:3, $\omega$-3) acids. These PUFAs are the precursors of a wide range of different eicosanoids, hormone-like substances protecting and maintaining structural and functional integrity of cells and cell components $[4,5,6]$. The $\omega-3$ and $\omega-6$ PUFAs are the necessary dietary nutrients for all vertebrates since their presence and ratio influence the status of lipid metabolism, susceptibility to the cardiovascular diseases, disturbances in neural and ophthalmic functions, allergic diseases, inflammations $[5,7,8,9,10]$. On the gene level these PUFAs control gene expression in different organs $[8,9]$ and tissues $[11,12,13]$. The substantial part (ca. 50-70\%) of dietary PUFAs is catabolyzed to meet energy requirements in human [14,15]. Only minor part of the dietary essential PUFAs undergoes the biotransformation to eicosahexaenic and docosahexaenic acids $[4,16]$, main fatty acids in the retinal membranes and the precursors of local cell-regulating hormones affecting the inflammation, bloodstream regulation, prepartum fetal loss, etc. [17].

Poultry meat contains large amounts of the PUFAs; however, the $\omega-6$ acids are predominant and the $\omega-6 / \omega-3$ PUFAs ratio is relatively large (12:1 in lipids of broiler meat and 25:1 in turkey) in compare to the recommended level (no more than 1:10).

With all aforementioned taken into account, the development of new technologies or modification of the existing 
foodstuffs involving the additional supplementation with ingredients with high biological and nutritive value is as urgent task for modern food industry.

The enrichment of foodstuffs with protein and fat ingredients usually involves the supplementation with collagen-rich animal meat products [18] and butter or vegetable (mostly sunflower) oils, respectively. All these ingredients are rich in $\omega-6$ PUFAs and the resulting dietary $\omega-6 / \omega-3$ PUFAs ratio is far from optimal. The use of the ingredients based on poultry eggs and their components can be the valuable alternative since these ingredients could be the source of high-quality protein containing almost all essential amino acids [19]. The content of valine and some other essential amino acids in chicken eggs is higher in compare to protein of broiler meat.

Egg lipids contain simple fats, phospholipids (including lecithin, cephalin, sphingomyelin), cerebrosides, sterides, sterines (cholesterol). Choline presents up to $75 \%$ of egg phospholipids; concentration of lecithin is 6-fold higher in compare to cholesterol promoting the better bioavailability of egg lipids. However, the most value ingredients within the eggs are essential PUFAs deficient in other standard foodstuffs in human diets.

Eggs also have certain important technological properties like foam and gel production, emulsifying ability, ability to make a product "airy". The most important technological factor is the gel producing ability of the albumen [20].

The coagulation of egg components is a prospective technology of maximal preservation of the useful properties of the eggs. The studies on the changes in the latter induced by different factors resulted in the development of protein-rich food ingredients based on the coagulated egg components (melange, albumen, yolk) with grainy texture [21]. The use of these ingredients as the additives to meat can increase the contents of full-value protein and fat in standard and functional food commodities to enhance their biological value.

The use of chopped meat-based semifinished foodstuffs (SFFs) in human diets requires the knowledge on the changes in nutritional and biological value which occur in the SFFs during the last stage of cooking, different types of thermal treatment. These types are known to differently affect the composition of the SFFs [21,22]. However, there is a lack of available data on the changes in the biological value of the SFFs after the thermal treatment; this knowledge is necessary for the formulation of diets for different categories and ages of consumers, receipts of special and functional nutrition. There is also a lack of information regarding the effects of thermal treatments on the combined SFFs containing poultry meat and egg-based ingredients.

The aim of the study presented was the investigation of the effects of different types of thermal treatment (cooking) on the parameters of biological value of the combined SFF containing broiler meat and coagulated chicken egg melange (CCEM).

\section{Materials and methods}

The SFF in this study was the cutlet-like semifinished product contained chopped broiler meat (55\%), CCEM (20\%), milk powder $(12 \%)$, wheat bread $(9 \%)$, dried onion (3\%), salt $(0.8 \%)$, and spices.

The CCEM was preliminary produced via the heating of acidified melange of chicken eggs until the formation of a clot with the texture similar to grainy curd [23]. The yield of CCEM was $82.7 \%$ of initial melange; CCEM produced contained $14.3 \%$ of protein and $12.1 \%$ of fat.

The types of the thermal treatment used for the cooking of the SFF included water boiling (water/SFF ratio 0.5:1.0), steam boiling, traditional techniques of braising, baking, and frying; the amino and fatty acid profiles of cooked SFF were compared to the respective parameters before the treatments.

The amino acid profiles were determined on Knauer analyzer; tryptophan by standard method according to Russian standard GOST 34132. The biological value of the protein within the treated products was assessed using amino acid balance coefficients calculated by the method of N. N. Lipatov [24]. The following criteria were used: amino acid score (AS); coefficient of rationality of amino acid composition (Rc); "comparable redundance" of essential fatty acids $(\sigma)$, utilitarian coefficient ( $\left(\mathrm{j}_{\mathrm{j}}\right)$.

Fatty acid profiles were determined via capillary gas-liquid chromatography. The total amounts of SFAs, MUFAs, and PUFAs were determined; their ratios and $\omega-6 / \omega-3$ PUFAs ratios were calculated.

The percentages of moisture, protein, and fat in the products were determined according to GOST 31470.

The temperature of the thermal treatments was controlled by the thermometer with the scale from -50 to $+300^{\circ} \mathrm{C}$ and maximum relative measurement error $\pm 0.5^{\circ} \mathrm{C}$.

\section{Results and discussion}

The preliminary comparative investigation of the amino and fatty acid profiles in the intact SFF with CCEM in compare to the SFF without CCEM supplementation has revealed the significant increases in the contents of essential amino acids: methionine by $35 \%$, valine and isoleucine by $22-23 \%$, threonine, leucine, phenylalanine, and lysine by $14-15 \%$ while the content of tryptophan in the CCEM-supplemented SFF has been slightly lower; the ratio of essential $\omega-6 / \omega-3$ PUFAs has been better in the CCEM-supplemented SFF. The conclusion has been made that the balance of the amino and fatty acids has been better in the supplemented product. The $\sigma$ criterion has been lower in the CCEM-supplemented SFF while the Rc criterion has been higher; these findings have evidenced the better biological value of this product.

The comparative investigation of the amino and fatty acid profiles in the CCEM-supplemented SFF after different types of thermal treatment (cooking) in compare to the intact one revealed that all treatments affected the contents of moisture, fat, and protein (Table 1). 
Table 1. The changes in basic nutritive parameters in the SFF depending on cooking (thermal treatment) type

\begin{tabular}{|l|c|c|c|}
\hline \multirow{2}{*}{ Treatment type } & \multicolumn{3}{|c|}{ Content, \% } \\
\hline Raw (untreated) & 70.9 & Fat & Protein \\
\hline Water boiled & 70.9 & 6.7 & 14.3 \\
\hline Steam boiled & 69.4 & 6.3 & 14.5 \\
\hline Braised & 69.6 & 6.5 & 15.3 \\
\hline Baked & 62.7 & 10.0 & 15.3 \\
\hline Fried & 65.2 & 10.3 & 18.1 \\
\hline
\end{tabular}

The moisture content underwent little changes during the thermal treatments. Moisture loss after braising, steam boiling, and frying was $1.3 ; 1.5$ and $5.7 \%$, respectively; the highest moisture loss was found for baking (8.2\%).

The thermal treatments resulted in the increases in protein content within the cooked SFF: baking by $3.8 \%$, frying by $1.8 \%$, braising and stream boiling by $1.0 \%$, water boiling by $0.2 \%$.

The changes in fat content in cooked SFF were different: braising, water and stream boiling resulted in the slight decreases in fat content while baking and frying increased this parameter by 3.0 and $3.3 \%$, respectively.
The study of amino acid profiles of the proteins of intact and cooked SFF revealed the trend to higher contents of essential amino acids after all types of cooking (Figure 1).

The limiting amino acid in raw SFF was lysine with AS criterion 0.68 units. Different types of thermal treatment resulted in different changes in the amino acid profiles of protein within the SFF. The least affected amino acid profiles (in compare to the raw SFF) were found for water and steam boiling. Braising and baking resulted in higher contents of essential amino acids; AS for essential amino acids in these cases were close to the reference levels (close to 1.0) with the exception of tryptophan (AS1.82). No limiting amino acids were found in baked SFF though AS for certain essential amino acids (leucine, lysine, threonine, tryptophan, phenylalanine, and tyrosine) were substantially higher than 1.0 (Table 2). The utilitarian coefficients aj (the content of essential amino acids in relation to the respective physiologic requirements of consumer) in the cooked SFF were close to the intact one.

The calculated criteria of biological value (coefficient of rationality of amino acid composition Rc and "comparable

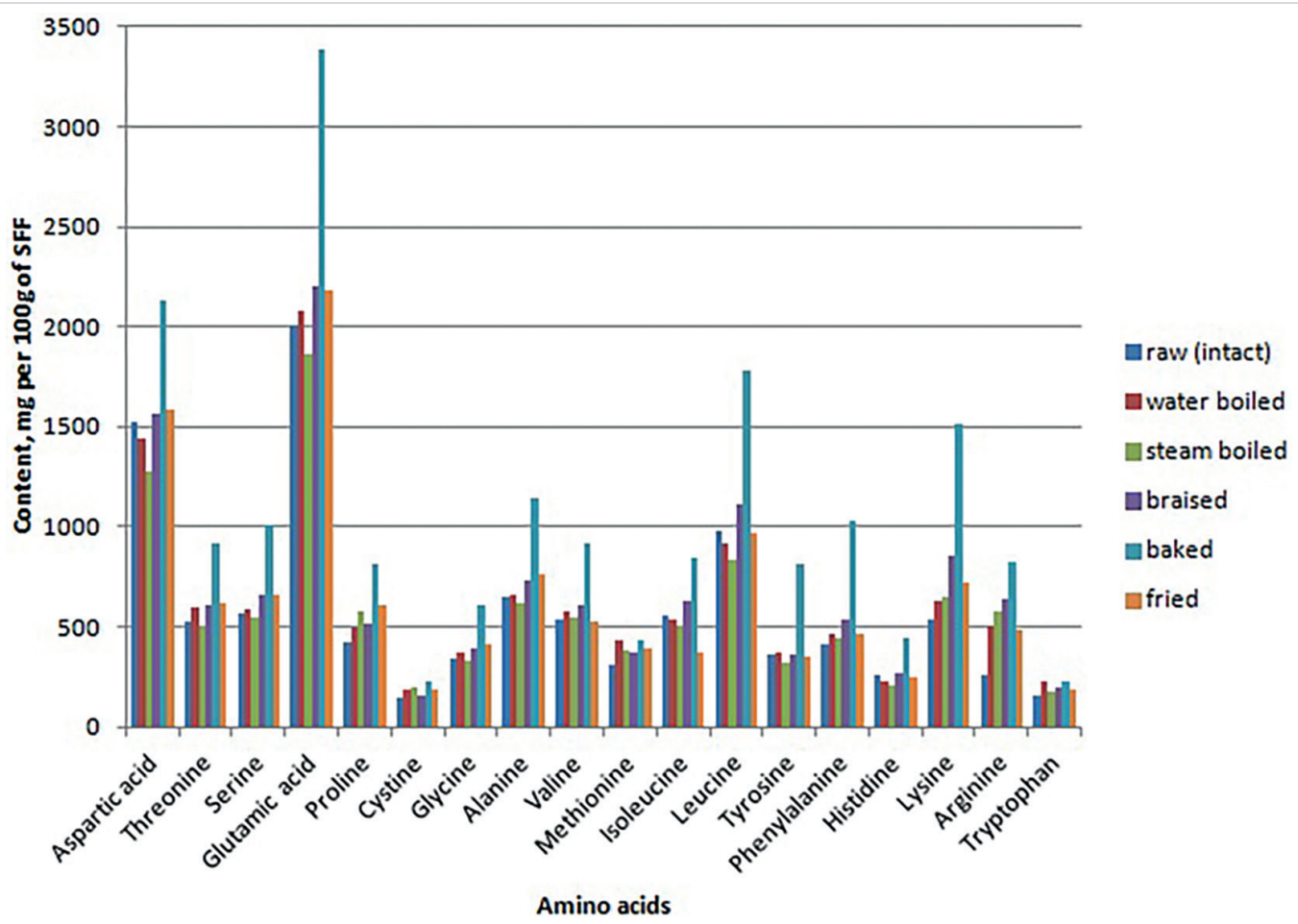

Figure 1. Amino acid profiles of the SFF depending on the type of the thermal treatment

Table 2. The essential amino acid scores (AS) and utilitarian coefficients (aj) in raw and cooked SFF

\begin{tabular}{|c|c|c|c|c|c|c|c|c|c|c|c|c|}
\hline \multirow{2}{*}{ Amino acids } & \multicolumn{2}{|c|}{ Raw } & \multicolumn{2}{|c|}{ Water boiled } & \multicolumn{2}{|c|}{ Steam boiled } & \multicolumn{2}{|c|}{ Braised } & \multicolumn{2}{|c|}{ Baked } & \multicolumn{2}{|c|}{ Fried } \\
\hline & AS & $\boldsymbol{a j}$ & AS & aj & AS & aj & AS & $\boldsymbol{\alpha} \mathbf{j}$ & AS & $\boldsymbol{a j}$ & AS & $a \mathbf{j}$ \\
\hline Valine & 0.76 & 0.89 & 0.79 & 1.00 & 0.72 & 1.00 & 0.80 & 1.00 & 1.02 & 1.00 & 0.65 & 0.89 \\
\hline Isoleucine & 0.98 & 0.69 & 0.92 & 0.86 & 0.83 & 0.87 & 1.03 & 0.78 & 1.17 & 0.87 & 0.58 & 1.00 \\
\hline Leucine & 0.98 & 0.69 & 0.91 & 0.87 & 0.78 & 0.92 & 1.04 & 0.77 & 1.41 & 0.72 & 0.86 & 0.67 \\
\hline Lysine & 0.68 & 1.00 & 0.79 & 1.00 & 0.78 & 0.92 & 1.02 & 0.78 & 1.52 & 0.67 & 0.82 & 0.71 \\
\hline Methionine+cystine & 0.91 & 0.75 & 1.23 & 0.64 & 1.08 & 0.67 & 0.98 & 0.82 & 1.03 & 0.99 & 1.42 & 0.41 \\
\hline Threonine & 0.92 & 0.74 & 1.03 & 0.77 & 0.83 & 0.84 & 1.00 & 0.80 & 1.26 & 0.81 & 0.96 & 0.60 \\
\hline Tryptophan & 1.11 & 0.61 & 1.54 & 0.51 & 1.19 & 0.61 & 1.82 & 0.44 & 1.29 & 0.79 & 1.15 & 0.50 \\
\hline Phenylalnine+tyrosine & 0.90 & 0.76 & 0.96 & 0.82 & 0.83 & 0.87 & 0.98 & 0.82 & 1.70 & 0.60 & 0.85 & 0.68 \\
\hline
\end{tabular}


redundance" of essential fatty acids $\sigma$ ) showed that water and steam boiling resulted in the best parameters of biological value of protein within the FFS (Table 3).

Table 3. The criteria of biological value of raw and cooked SFF

\begin{tabular}{|l|c|c|c|} 
Treatment type & $\begin{array}{c}\text { Coefficient of } \\
\text { rationality of } \\
\text { amino acid } \\
\text { composition Rc }\end{array}$ & $\begin{array}{c}\text { “Comparable } \\
\text { redundance" of } \\
\text { essential fatty } \\
\text { acids } \sigma\end{array}$ & $\begin{array}{c}\text { Biological } \\
\text { value }\end{array}$ \\
\hline Raw (untreated) & 0.77 & 10.61 & 77.5 \\
\hline Water boiled & 0.83 & 7.12 & 76.9 \\
\hline Steam boiled & 0.86 & 5.57 & 84.0 \\
\hline Braised & 0.80 & 9.04 & 71.6 \\
\hline Baked & 0.76 & 11.17 & 70.7 \\
\hline Fried & 0.67 & 17.79 & 66.9 \\
\hline
\end{tabular}

The study of the individual fatty acid profiles in the cooked CCEM-supplemented SFF (Table 4) and total contents of SFAs, MUFAs, and PUFAs (Table 5) revealed that water boiling, steam boiling, braising, and baking slightly increase the total SFA content (by 1.37; 1.89; 4.32 and 2.29\%, respectively); the most substantial changes were found after braising. The total contents of MUFAs with these treatment types were similar to the level of the raw product.

Table 4. Fatty acid (FA) profiles in raw and cooked SFF

\begin{tabular}{|c|c|c|c|c|c|c|c|}
\hline \multirow[b]{2}{*}{ FA } & \multirow[b]{2}{*}{ FA type } & \multicolumn{6}{|c|}{ Content, $\%$ of total FA } \\
\hline & & 胥 & 离 & 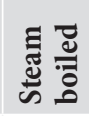 & 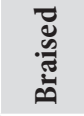 & 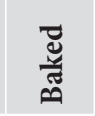 & 苞 \\
\hline Butyric & C4:0 & 0.13 & 0.10 & 0.09 & 0.13 & 0.09 & 0.12 \\
\hline Capronic & C6:0 & 0.09 & 0.07 & 0.07 & 0.08 & 0.07 & 0.08 \\
\hline Caprylic & C8:0 & 0.06 & 0.05 & 0.05 & 0.06 & 0.05 & 0.06 \\
\hline Caprinic & C10:0 & 0.14 & 0.13 & 0.14 & 0.15 & 0.14 & 0.12 \\
\hline Lauric & C12:0 & 0.17 & 0.18 & 0.18 & 0.18 & 0.17 & 0.14 \\
\hline Tridecanoic & C13:0 & 0.03 & 0.03 & 0.03 & 0.13 & 0.03 & 0.05 \\
\hline Myristinic & C14:0 & 0.89 & 0.93 & 0.97 & 1.02 & 0.94 & 0.75 \\
\hline Myristoleic & C14:1 & 0.14 & 0.14 & 0.13 & 0.07 & 0.14 & 0.10 \\
\hline Pentadecanoic & C15:0 & 0.17 & 0.17 & 0.20 & 0.47 & 0.18 & 0.22 \\
\hline Palmitic & C16:0 & 22.43 & 23.53 & 24.20 & 25.49 & 24.12 & 19.42 \\
\hline Palmitoleic & C16:1 & 3.93 & 3.93 & 3.94 & 3.77 & 3.85 & 3.11 \\
\hline Margaric & C17:0 & 0.14 & 0.14 & 0.15 & - & 0.15 & 0.11 \\
\hline Margaroleic & C17:1 & 0.05 & 0.05 & 0.06 & - & 0.07 & 0.05 \\
\hline Stearic & C18:0 & 6.50 & 6.79 & 6.96 & 7.67 & 7.11 & 6.07 \\
\hline Oleic & C18:1 & 35.33 & 36.31 & 36.71 & 36.31 & 35.52 & 32.95 \\
\hline Elaidinic & C18:1(t9) & 1.62 & 1.64 & 1.66 & 1.57 & 1.63 & 1.39 \\
\hline Linolic & C18:2(n6) & 25.76 & 24.24 & 23.06 & 22.28 & 23.32 & 33.72 \\
\hline$\gamma$-linoleic & C18:3(n6) & 0.18 & 0.13 & 0.13 & - & 0.12 & 0.15 \\
\hline a-linoleic & C18:3(n3) & 0.42 & 0.35 & 0.32 & 0.28 & 0.33 & 0.33 \\
\hline Arachidonic & C20:0 & 0.08 & 0.08 & 0.09 & - & 0.09 & 0.11 \\
\hline Gondoinic & C20:1 & 0.34 & 0.38 & 0.38 & - & 0.38 & 0.35 \\
\hline Eicosatrienoic & C20:3 & 0.43 & 0.41 & 0.31 & 0.34 & 0.33 & 0.30 \\
\hline Geneicosaenoic & C21:0 & 0.22 & 0.23 & 0.20 & - & 0.20 & 0.14 \\
\hline Begenic & C22:0 & - & - & - & - & - & 0.18 \\
\hline Docosenoic & C22:1 & 0.72 & - & - & - & - & - \\
\hline
\end{tabular}

Table 5. The contents of total SFAs, MUFAs, and PUFAs in raw and cooked SFF, \% of total FA

\begin{tabular}{|c|c|c|c|c|c|c|}
\hline \multirow{2}{*}{ Total } & \multicolumn{7}{|c|}{ Cooking type } \\
& Raw & $\begin{array}{c}\text { Water } \\
\text { boiled }\end{array}$ & $\begin{array}{c}\text { Steam } \\
\text { boiled }\end{array}$ & Braised & Baked & Fried \\
\hline SFAs & 31.05 & 32.42 & 33.34 & 35.37 & 33.34 & 27.56 \\
\hline MUFAs & 42.16 & 42.45 & 42.83 & 41.72 & 41.59 & 37.94 \\
\hline PUFAs & 26.79 & 25.13 & 23.83 & 22.90 & 24.10 & 34.49 \\
\hline
\end{tabular}

The slight changes in the fatty acid profiles in cooked SFF were primarily related to the decreases in the PUFAs contents; in water-boiled, steam-boiled, braised and baked SFF this decrease was $2.64 ; 2.96 ; 3.88$ and $2.68 \%$, respectively. The $\omega-6 / \omega-3$ PUFAs ratios were affected more substantially especially in the case of braising; the least change in this ratio was found in water-boiled SFF. Generally, all types of cooking (thermal treatments) had little influence on the fatty acid balance.

\section{Conclusion}

The amino and fatty acid profiles in the SFF supplemented with coagulated chicken egg melange after different types of cooking (thermal treatments) were studied.

Different types of cooking differently affected the contents of protein, fat, amino and fatty acids within the product.

The least changes in the parameters of biological and nutritive value of the SFF was found with water- and steam-boiling. Braising and baking were found to increase the contents of essential amino acids; the resulting contents of the latter were close to the respective reference levels (AS close to 1.0) with the exception of tryptophan (AS1.82). No limiting amino acids were found in baked SFF though AS for certain essential amino acids (leucine, lysine, threonine, tryptophan, phenylalanine, and tyrosine) were substantially higher than 1.0 (i. e. higher in compare to the reference levels).

The highest biological value (as revealed by the coefficient of rationality of amino acid composition Rc and "comparable redundance" of essential fatty acids $\sigma$ ) had steam-boiled SFF; overall index of biological value for this treatment was the highest (84.0) in compare to the raw SFF (77.5).

The effects of different types of thermal treatment on the fatty acid profiles of SSF were insignificant. The slight changes in the fatty acid profiles in cooked SFF were primarily related to the increases in the SFAs and decreases in the PUFAs contents; in water-boiled, steam-boiled, braised and baked SFF this decrease was $2.64 ; 2.96 ; 3.88$ and $2.68 \%$, respectively. The $\omega-6 / \omega-3$ PUFAs ratios were affected more substantially especially in the case of braising. 
1. Tutelyan, V.A. (2000). On the correction of micronutrient deficits for the improvement of nutrition and health of infant and adult population on the threshold of the third millennium. Voprosy pitaniya, 4, 6-7. (in Russian)

2. Pokrovsky, A.A. (1994). Biochemical substantiation of the development of the foodstuffs with increased biological value. Voprosy Pitaniia, 1, 1-3. (in Russian)

3. Erastov, G.M. (2014). The nutritional value of poultry meat. Ptitsevodstvo, 3, 28-30. (in Russian)

4. Wall, R., Ross, R.P., Fitzgerald, G.F., Stanton, C. (2010). Fatty acids from fish: the anti-inflammatory potential of long-chain omega-3 fatty acids. Nutrition Reviews, 68(5), 280-289. https://doi. org/10.1111/j.1753-4887.2010.00287.x

5. Vasilyev, A.V., Sharanova, N.E., Kulakova, S.N. (2014). Nutrimetabolomics - the new stage of biochemistry of nutrition. The role of nutrilipidomic analysis. Voprosy Pitaniia, 83(1), 4-11. (in Russian)

6. Farooqui, A.A. (2012). n-3 fatty acid-derived lipid mediators in the brain: new weapons against oxidative stress and inflammation. Current Medicinal Chemistry, 19(4), 532-543. https://doi. org/10.2174/092986712798918851

7. Golberg, R.J., Katz, J. (2007). A meta-analysis of the analgesic effects of omega-3 polyunsaturated fatty acid supplementation for inflammatory joint pain. Pain, 129(1), 210-223. https://doi. org/10.1016/j.pain.2007.01.020

8. Leaf, A. (2006). Prevention of sudden cardiac death by n-3 polyunsaturated fatty acids. Fundamental and Clinical Pharmacology, 20(6), 525-538. https://doi.org/10.1111/j.14728206.2006.00438.x

9. SanGiovanni, J.P., Chew, E.Y. (2005). The role of omega-3 long-chain polyunsaturated fatty acids in health and disease of the retina. Progress in Retinal and Eye Research, 24(1), 87-138. https://doi.org/10.1016/j.preteyeres.2004.06.002

10. Uauy, R., Dangour, A.D. (2006). Nutrition in brain development and aging: role of essential fatty acids. Nutrition Reviews, 64, S24S33. https://doi.org/10.1111/j.1753-4887.2006.tb00242.x

11. Barceli-Coblijn, G., Hogyes, E., Kitajka, K., Puskas, L.G., A. Zvara, A., Hackler, L., Nyakas, C., Penke, Z., Farkas, T. (2003). Modification by docosahexaenoic acid of age-induced alterations in gene expression and molecular composition of rat brain phospholipids. Proceedings of the National Academy of Sciences, 100(20), 11321-11326. https://doi.org/10.1073/ pnas.1734008100

12. Puskos L. G., Kitijka K., Nyakas, Barcelo-Coblijn, G., Farkas, T. (2003). Short-term administration of omega-3 fatty acids from fish oil results in increased transthyretin transcription in old rat hippocampus. Proceedings of the National Academy of Sciences, 100(4) 6 1580-1585. https://doi.org/10.1073/ pnas. 0337683100

13. Clarke, S.D. (2001). Polyunsaturated fatty acid regulation of gene transcription: a molecular mechanism to improve the met- abolic syndrome. The Journal of Nutrition, 131(4), 1129-1132. https://doi.org/10.1093/jn/131.4.1129

14. Duplus, E., Glorian, M. (2000). Fatty acid regulation of gene transcription. Journal of Biological Chemistry, 275(40), 3074930752. https://doi.org/10.1074/jbc.R000015200

15. Wahle, K.W.J., Rotondo, D., Heys, S.D. (2003). Polyunsaturated fatty acids and gene expression in mammalian systems. Proceedings of the Nutrition Society, 62(2), 349-360. https://doi. org/10.1079/pns2003249

16. Broadhurst, C.L., Wang, Y., Crawford, M.A., Cunnane, S.C., Parkington, J.E., Schmidt, W.F. (2002). Brain-specific lipids from marine, lacustrine, or terrestrial food resources: potential impact on early African Homo sapiens. Comparative Biochemistry and Physiology Part B: Biochemistry and Molecular Biology, 131(4), 653-673. https://doi.org/10.1016/s10964959(02)00002-7

17. Umegaki, K., Hashimoto, M., Yamasaki, H., Fujii, Y., Yoshimura, M., Sugisawa, A., Shinozuka, K. (2001). Docosahexaenoic acid supplementation-increased oxidative damage in bone marrow DNA in aged rats and its relation to antioxidant vitamins. Free Radical Research, 34(4), 427-435. https://doi. org/10.1080/10715760100300361

18. Davis, B.C., Kris-Etherton, P.M. (2003). Achieving optimal essential fatty acid status in vegetarians; current knowledge and practical implications. The American Journal of Clinical Nutrition, 78(3), 640S-646S. https://doi.org/10.1093/ajcn/78.3.640s 19. Omarov, R.S., Sycheva, O.V., Shlykov, S.N. (2011). Animal proteins in the technologies of meat products. Meat branch, 3(99), 36-38. (in Russian)

20. Stefanova, I.L., Mazo, V.K., Mokshantseva, I.V., Klimenkova, A. Yu. (2017). The perspectives of the use of egg albumen within functional food ingredients. Poultry and Chicken Products, 1, 43-45. (in Russian)

21. Stefanova, I.L., Shakhnazarova, L.V., Klimenkova, A. Yu (2019). Technology development for eggs and egg components further processing and it introduction to industry. Proceedings scientific and technical support efficiency and quality production of agricultural products. 246-257. https://doi.org/10.30975/9785-9909889-2-7-2019-1-1-246-257 (in Russian)

22. Nys, Y., Bain, M., Immerseel, F.V. (2011). Improving the Safety and Quality of Eggs and Egg Products: Vol. 1: Egg Chemistry, Production and Consumption. Woodhead Publishing Limited. - 602 p. ISBN: 9781845697549

23. Stefanova, I.L., Shakhnazarova, L.V., Klimenkova, A. Yu., Krasyukov, Yu.N. (2017). The investigation of the process of coagulation of egg melange and qualitative characteristics of the resulting product. Poultry and Chicken Products, 5, 49-53. (in Russian) 24. Lipatov, N.N., Lisitsyn, A.B., Yudina, S.B. (1996). The advancement of the methods of design of the biological value of foodstuffs. Storage and processing of farm products, 2, 24-25. (in Russian) 


\section{AUTHOR INFORMATION}

Isabella L. Stefanova - doctor of technical sciences, chief researcher, Laboratory Of Infant And Special Poultry Products, All-Russian Scientific Research Institute of Poultry Processing Industry - Branch of the Federal State Budget Scientific Institution Federal Scientific Center "All-Russian Research and Technological Poultry Institute" of Russian Academy of Sciences, 142552, Moscow region, Rzhavki township. Tel.: +7-495-944-53-30, E-mail: dp.vniipp@mail.ru

ORCID: https://orcid.org/0000-0002-4394-5149

* corresponding author

Liudmila V. Shakhnazarova - candidate of technical sciences, leading researcher, Laboratory Of Infant And Special Poultry Products, AllRussian Scientific Research Institute of Poultry Processing Industry - Branch of the Federal State Budget Scientific Institution Federal Scientific Center "All-Russian Research and Technological Poultry Institute" of Russian Academy of Sciences, 142552, Moscow region, Rzhavki township. Tel: +7-495-944-53-30, E-mail: dp.vniipp@mail.ru

ORCID: https://orcid.org/0000-0001-5671-6495

Anastasia Yu. Klimenkova - researcher, Laboratory Of Infant And Special Poultry Products, All-Russian Scientific Research Institute of Poultry Processing Industry - Branch of the Federal State Budget Scientific Institution Federal Scientific Center "All-Russian Research and Technological Poultry Institute" of Russian Academy of Sciences, 142552, Moscow region, Rzhavki township. Tel.: +7-495-944-53-30, E-mail: dp.vniipp@mail.ru ORCID: https://orcid.org/0000-0002-3272-9467

Inna M. Sorokina - researcher, Testing laboratory center, All-Russian Scientific Research Institute of Poultry Processing Industry — Branch of the Federal State Budget Scientific Institution Federal Scientific Center "All-Russian Research and Technological Poultry Institute" of Russian Academy of Sciences, 142552, Moscow region, Rzhavki township.Tel.: +7-495-944-53-30, E-mail: dp.vniipp@mail.ru ORCID: https://orcid.org/0000-0001-7859-4011

All authors bear responsibility for the work and presented data.

All authors made an equal contribution to the work.

The authors were equally involved in writing the manuscript and bear the equal responsibility for plagiarism.

The authors declare no conflict of interest.

Received 25.06.2020 Accepted in revised 15.09.2020 Accepted for publication 28.09.2020 